Revista Eletrônica em Gestão, Educação e Tecnologia Ambiental

REGET/UFSM (e-ISSN: 2236-1170).

\title{
ANÁLISE DE PROJETO E OPERAÇÃO DE ESTAÇÃO DE TRATAMENTO DE ESGOTO EM CRAVINHOS (SP), BRASIL
}

\author{
Elias Antonio Vieira
}

\section{RESUMO}

O presente estudo trata do procedimento empregado por seu autor na avaliação de um projeto de implantação de Estação de Tratamento de Esgoto - ETE em Cravinhos (SP). O método empregado constituiu-se de levantamento bibliográfico e da análise da documentação do projeto. O objetivo do trabalho é subsidiar os interessados no entendimento do funcionamento desse tipo de empreendimento, assim como contribuir com a resolução de suas eventuais falhas. Os resultados do presente estudo indicaram lacunas e ou inconformidades no projeto em relação ao funcionamento da ETE.

Palavras-chave: Esgoto. Impactos ambientais. Estação de Tratamento de Esgoto.

\section{ABSTRACT}

\section{Analysis of project and operation of wastewater treatment plant in Cravinhos, SP, Brazil}

The present study deals with the procedure employed by the author in the evaluation of a project to establish Wastewater Treatment Plant - WWTP in Cravinhos (SP). The method used consisted of a literature review and analysis of project documentation. The aim of this work is to support those interested in understanding the functioning of this type of project, as well as contributing to the resolution of their faults. The results of this study indicated weaknesses and unconformities in the project in relation to the operation of the WWTP.

Keywords: Wastewater. Envinronmental impacts. Wastewater Treatment Plant.

\section{INTRODUÇÃO}

O que é e quais as vantagens e desvantagens de uma Estação de Tratamento de Esgoto ETE de lodo ativado? Quais as características, os problemas operacionais, e as indicações de possíveis soluções em relação à ETE de Cravinhos, SP?

Estas são as questões problema que norteiam o presente estudo para o qual se levantaram dados para fundamentar a resposta.

Com a finalidade de contextualizar a realidade espacial, social e econômica de Cravinhos, apresentam-se os dados conforme seguem.

O município citado (FIGURA 1) foi instalado no ano 1898 e integra a região de Ribeirão Preto no Nordeste do Estado de São Paulo. Situa-se na latitude 2120'25" Sul e longitude 47-43'46" Oeste e altitude de 788 metros. O fato de seu sítio ter sido uma fazenda em que havia pequenos cravos plantados originou o nome. Sua população estimada, em 2008, de 30.647 habitantes está distribuída em 28 lugares assim denominados: Alto das Acácias, Centro, Conjunto 


\section{Revista Eletrônica em Gestão, Educação e Tecnologia Ambiental REGET/UFSM (e-ISSN: 2236-1170).}

Habitacional Trajano Stella, Jardim das Acácias, Jardim Alvorada, Jardim Anhanguera, Jardim Bela Vista, Jardim Bothanico, Jardim Independência, Jardim Itapuã, Jardim Paulista, Jardim Primavera, Jardim Santa Cruz, Nova Cravinhos, Parque industrial Alvorada, Parque São Francisco, Parque São José, Residencial Jardim Santana, Sumaré, Vila Claudia, Vila Pio XII, Vila Santa Cecília, Vila Viegas e nos conjuntos habitacionais Francisco Castilho I e II, Itamarati, João Berbel, Osvaldo Luís Netto (WIKIPÉDIA, 2011).

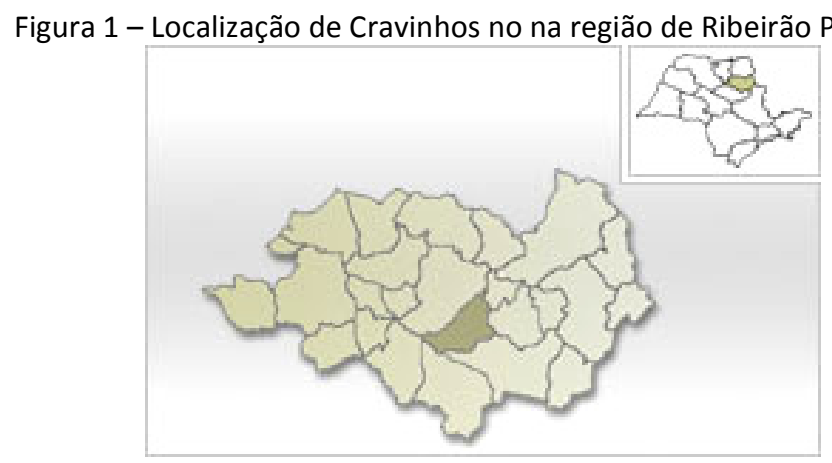

Fonte: SEADE (2011)

Outros dados da realidade da população desta cidade, em 2010, comparados aos do país, citados entre parêntesis, revelam melhor posição do município na quase totalidade dos quesitos. De acordo com o IBGE (2011; 2011a), SEADE (2011) e WIKIPÉDIA (2011) a densidade demográfica de Cravinhos é de 91,3 habitantes por $\mathrm{km}^{2}(22,4)$; a mortalidade infantil, por mil habitantes, até um ano de 10,5 (29,6); expectativa de vida, em anos, de 74,3 (68); taxa de fecundidade, por mulher, de 2,3 (2,3); taxa de alfabetização de $90,96 \%(86,4 \%)$; rendimento médio do trabalho formal de $R \$ 1.458,77$ ( $R \$ 1.550,26)$, e Índice de Desenvolvimento Humano - IDH de 0,815 $(0,699)$.

A ETE, objeto do presente estudo situa-se, no final da malha urbana, sentido Nordeste deste do município de Cravinhos.

As informações levantadas neste trabalho permitiram a comparação entre os dados de projeto oferecidos pela autarquia municipal responsável da ETE e a realidade. A escolha do objeto de estudo se deu pelos impactos sociais, ambientais e econômicos provocados em virtude de seu funcionamento não atender integralmente as normas técnicas.

Com base nos resultados conseguidos constatam-se inconformidades entre os dados de projeto e a realidade operacional da ETE ante aos padrões de eficiência normalmente aceitos.

Portanto, a finalidade deste estudo é apresentar subsídios, aos interessados na temática, para entendimento dos fatores contribuintes com as falhas e funcionamento, os impactos ambientais delas resultantes e induzir reflexões sobre possíveis medidas para sua prevenção.

Desse modo, a pesquisa se conduziu através de levantamentos bibliográficos, com apoio de manuais e sítios eletrônicos, da rede mundial de computadores relacionados ao seu intuito. De tal modo fornece dados básicos sobre a legislação e as normas sobre tratamento de esgoto. Também demonstra os resultados da análise dos documentos do projeto da ETE em comparação com seu funcionamento prático.

Portanto, o limite do presente estudo é conhecer o que é e quais os tipos, as vantagens e desvantagens desse empreendimento, assim como as características, os problemas operacionais, ambientais, e suas soluções, no caso da ETE de Cravinhos, SP. 


\section{Revista Eletrônica em Gestão, Educação e Tecnologia Ambiental REGET/UFSM (e-ISSN: 2236-1170).}

Quanto ao objetivo este trabalho busca levantar, e analisar, dados principais do projeto comparando-os com as normas e a realidade visando conhecer a relação entre o cumprimento das diretrizes normativas, e a eficiência operacional desse empreendimento.

A escolha do objeto de estudo desta pesquisa justifica-se por três motivos principais. 0 primeiro é o fato de o tratamento de esgoto, juntamente com o da água e do lixo, estar incluído no conceito de saneamento básico e ter efeito direto nas condições de saúde da população, conforme se verifica na definição seguinte.

O conjunto de ações, entendidas fundamentalmente como de saúde pública, compreendendo o abastecimento de água em quantidade suficiente para assegurar a higiene adequada e o conforto, com qualidade compatível com os padrões de potabilidade; coleta, tratamento e disposição adequada dos esgotos e dos resíduos sólidos; drenagem urbana de águas pluviais e controle ambiental de roedores, insetos, helmintos e outros vetores e reservatórios de doenças (BORJA; MORAIS, 2011 p.5).

O segundo motivo deste estudo baseia-se na necessidade de se produzir, e disseminar, conhecimento para facilitar o controle social sobre os impactos de diversas naturezas, e magnitudes, caso os serviços de saneamento, em especial o de tratamento de esgoto, não sejam conduzidas em conformidade com as normas técnicas e legais. E o terceiro leva em consideração o fato de as falhas de projeto, e ou operacionais, da ETE gerar prejuízos sociais, ambientais e econômicos à comunidade.

\section{MÉTODO E TÉCNICA}

Em relação ao método, a pesquisa foi delineada através de seus objetivos, dos procedimentos de coleta de dados, e do foco de abordagem (ANDRADE, 2001). Por conseguinte, sua classificação quanto aos objetivos é exploratória, visto que se propõe a fornecer uma visão geral, do tema pesquisado, podendo facilitar a formulação de novos problemas, e hipóteses, em pesquisas futuras. Quanto ao modo pelo qual se coletaram os dados é bibliográfico, pois, se levantou dados em artigos, leis, normas técnicas, teses, entre outros. Quanto à abordagem do problema, a pesquisa é qualitativa (VERGARA 1997). Como já se mencionou, cabe lembrar que esta última classificação, a pesquisa se restringe a verificar a conformidade da documentação ao projeto, às normas e à realidade operacional da ETE de Cravinhos.

No que tange à técnica da pesquisa, em primeiro lugar se obteve os documentos do projeto do empreendimento aprovados pela Municipalidade. Em seguida se levantaram os conteúdos no formado eletrônico, através de sítios de busca, nas páginas da rede mundial de computadores, que apresentavam resultados de pesquisas sobre o tema. Nessa etapa foram pesquisadas frases ou palavras-chave relacionadas às leis, manuais, normas e resoluções sobre saneamento básico e ambiental. E, por último o autor do presente estudo fez visitas em campo para comparar os dados dos documentos com a realidade. 


\section{Revista Eletrônica em Gestão, Educação e Tecnologia Ambiental \\ REGET/UFSM (e-ISSN: 2236-1170).}

\section{CARACTERÍSTICA DE ESTAÇÃO DE TRATAMENTO DE ESGOTO - ETE}

Neste tópico se transcreve, com adaptações e simplificações, o conceito de ETE, o tipo operacional de lodo ativado, as vantagens e desvantagens entre as opções técnicas de tratamento de esgoto citadas por CASAN (2011). Não foram abordadas as técnicas, também citadas pelo autor, de tratamento de esgoto por meio de lagoas de estabilização, e filtro biológico, em virtude de não terem sido utilizadas na configuração operacional da ETE de Cravinhos.

Conceito:

ETE - Estação de Tratamento de Esgoto é a unidade operacional do sistema de esgotamento sanitário que através de processos físicos, químicos ou biológicos removem as cargas poluentes do esgoto, devolvendo ao ambiente o produto final, efluente tratado, em conformidade com os padrões exigidos pela legislação ambiental (CASAN, 2011 p. 1).

Tipo:

Lodo ativado ou biológico

Refere-se aos flocos formados no processo biológico da etapa da remoção da matéria orgânica do esgoto em que interagem oxigênio, agitação mecânica, crescimento e atuação de microorganismos. Esse processo oferece duas alternativas de tratamento: 1) aeração prolongada e; 2) valo de oxidação.

A sequência operacional da aeração prolongada ocorre da seguinte maneira:

O pré-tratamento constituído do gradeamento composto por duas grades mecanizadas, cuja função é reter os rejeitos sólidos; e desarenador para remover a areia, e materiais indevidamente carreados pelo sistema de coleta de esgoto.

O tratamento secundário é composto das seguintes unidades:

Seletor biológico - mistura o esgoto bruto afluente com lodo ativado proveniente do processo de tratamento de aeração prolongada, evitando o desenvolvimento de microorganismos indesejáveis e melhorando a sedimentação do lodo.

Câmara de desnitrificação - reduz o nitrato [um tipo de sal] sob a ação de microorganismos.

Tanques de aeração - dispositivos equipados com aeradores mecânicos, de eixo vertical, apoiados em plataformas de concreto. O oxigênio introduzido propicia o desenvolvimento de bactérias aeróbias [microorganismos que dependem de ar para sobreviver] que irão digerir a matéria orgânica e o material da transformação do nitrogênio orgânico do esgoto.

Decantador secundário - nesta unidade os flocos formados nos tanques de aeração se sedimentam e são encaminhados a um poço central a partir do qual uma canalização pressurizada faz sua recirculação ou descarte do excesso.

Adensadores de lodo - [...] reduz a quantidade de água contida no lodo sedimentado nos decantadores.

Sistema de desidratação - esta unidade é composta de tanque de armazenamento de lodo adensado, com removedor mecânico, e sistema de recalque para sua transferência e précondicionamento, com suspensão de cal e de solução de polieletrólito [substância utilizada em processos de decantação de materiais].

Prensa desaguadora - [...] produz torta de lodo com $18 \%$ a $20 \%$ de umidade a qual é encaminhada até o local de estocagem através de correia transportadora para posterior disposição em aterro sanitário. 


\section{Revista Eletrônica em Gestão, Educação e Tecnologia Ambiental REGET/UFSM (e-ISSN: 2236-1170).}

Já a sequência operacional do valo de oxidação, por sua vez, ocorre nas unidades mais simples conforme segue.

Dispositivo de entrada: caixa de passagem e de distribuição, quando houver mais de um valo, que podem ser precedidos por sistema de gradeamento e medição;

Tanque de aeração: [...] seu funcionamento requer sejam mantidos os critérios estabelecidos para a velocidade média do fluxo de $0,3 \mathrm{~m} / \mathrm{s}$ durante o período de operação e que o fluxo escoe sem a possibilidade de zonas mortas. O esgoto é submetido a um processo de aeração onde ocorre a oxidação biológica [decomposição da matéria orgânica por bactérias], [...] promove o crescimento de flocos biológicos e consequentemente a redução da DBO (Demanda bioquímica de Oxigênio).

Dispositivo de saída: são projetados em função do tipo de operação, que poderá exigir fluxo contínuo ou intermitente.

O significado dos termos nitrato e oxidação biológica colocados entre colchetes nos parágrafos anteriores foram obtidos de Michaellis (2000).

Para CASAN (2011) o processo de tratamento de esgotos por lodo ativado ou biológico antes descrito apresenta:

Vantagens

- exige pouca área para implantação;

- maior eficiência no tratamento e;

- maior flexibilidade de operação.

Desvantagens

- custo operacional elevado;

- controle laboratorial diário e;

- operação mais delicada.

\section{ANÁLISES DO PROJETO ANTE A OPERAÇÃO DA ETE DE CRAVINHOS}

Os dados técnicos da rede coletora, do coletor tronco, interceptor e emissário e suas eventuais interferências operacionais no sistema de tratamento de esgoto não constaram de documento específico nem do projeto, por isso não foram analisados.

Análise do projeto:

Verificou-se que o período para cálculo da vida útil da ETE é de vinte anos (2003-2023).

A população atendida de fim de plano (2023) é de 40.000 habitantes.

A justificativa da escolha da tecnologia para o tratamento na forma de uma lagoa aerada (uso de aeradores elétricos) mais duas de decantação, e duas de lodo, consta do item 2 do projeto.

Chamou a atenção do autor desta pesquisa o fato de o projeto mencionar o custo de US\$ 63.000 [cerca de $\mathrm{R} \$ 190.000,00$ ], em 2004, para a opção tecnológica escolhida (2ª mais cara entre as três opções citadas), e seu custo real ter alcançado cerca de $\mathrm{R} \$ 1.600 .000,00$ até o momento. Vale ressaltar que este valor ultrapassou em mais de três vezes a opção de maior valor (uso de reator anaeróbio).

Outros fatos também chamaram à atenção:

10 - o cronograma físico financeiro da ETE não constou do projeto. 


\section{Revista Eletrônica em Gestão, Educação e Tecnologia Ambiental REGET/UFSM (e-ISSN: 2236-1170).}

2 - a citação de que o custo de operação, e manutenção, do sistema escolhido é "muito pequeno" não é adequada, como parâmetro de análise, por não definir valor.

3ㅇ - a citação de que a necessidade de mão-de-obra para a operação deste modelo de ETE é "eventual" contradiz com o Manual de Operação do Sistema de Tratamento dos Esgotos Domésticos do Município de Cravinhos (SP), do autor do projeto. Em seu item 2 determina-se que "a operação do sistema deverá ser feita por um profissional da prefeitura [...]. Também alerta que "o acompanhamento do processo de tratamento envolve a observação [e limpeza manual] permanente do acúmulo de rejeitos sólidos na grade, a vazão de esgotos na calha Parshall e o funcionamento dos aeradores".

4ํ - o fato de o item 6 do projeto recomendar a limpeza da caixa de areia a cada três dias.

5o - o Manual indica seja observada a lâmina de esgoto, de projeto, para impedir o crescimento de vegetação que daria suporte aos ovos, e larvas, de mosquitos; a prevenção da invasão do sistema por moluscos [caracóis, lesmas, caramujos etc.], plantas aquáticas, e o impedimento de criação de peixes nas lagoas. 6ㅇ - A previsão de consumo de energia elétrica do sistema escolhido $(118,26 \mathrm{Kw} /$ habitante/ano) é $38,6 \%$ maior que a opção de reator anaeróbio (a outra opção - lagoa de estabilização - não requer uso de energia elétrica), conforme citação no projeto.

É preciso destacar que o projeto não previu o dispositivo de armazenamento provisório e a destinação final dos rejeitos sólidos retidos no gradeamento, os quais deveriam ser colocados numa caçamba fechada e depois transportados até um aterro sanitário.

Na visita do dia 6/10/11 se constatou que foi improvisada uma tubulação externa ligando o prolongamento da caixa de areia à lagoa aerada. Esse dispositivo, segundo o técnico responsável pela ETE, teria a finalidade de aumentar a vazão de esgoto e, com isso, evitar transbordamento no solo.

O esgoto bruto afluente é recalcado do ponto terminal do emissário até a entrada na ETE, por elevatória e linha de recalque, de acionamento elétrico. Esse dispositivo não foi citado no projeto.

O cálculo, de projeto, da vazão de esgoto afluente para a fase inicial (final de 2010), com população de 30.000 pessoas, e o fim de período (2023) considerou, respectivamente, 69,4 e 92,6 $\mathrm{I} / \mathrm{s}$ (litros por segundo). Desses totais $80 \%$ se tornam esgoto.

O técnico responsável informou ao autor desta pesquisa que a cidade de Cravinhos teria indicadores de vazão, na fase inicial (2010), superiores aos do projeto. Como se observou num tópico do projeto, cita $0,1666 \mathrm{~m}^{3} / \mathrm{s}$ (metros cúbicos por segundo), como valor de vazão de entrada do esgoto no sistema, mas noutro tópico do projeto este valor se refere a hipótese de vazão máxima. Convém acrescentar que o autor do projeto da ETE trabalha com projeção de população de 31.400 habitantes para o ano de 2010 (inicio de plano), e vazão e altura de lâmina de esgoto, respectivamente, de $73,0 \mathrm{l} / \mathrm{s}$ e 0,15 m. Na situação anterior alguns dados tiveram valores menores, ou seja, população contribuinte de 30.000 habitantes e 69,4 l/s de vazão de esgoto. Estes dados precisam ser cotejados, e comprovados, e ou ajustados à realidade, para subsidiar o plano de gerenciamento e orientar eventual intervenção no sistema de funcionamento da ETE. Além disso, este empreendimento foi projetado para receber esgoto de origem doméstica, mas, segundo o seu responsável técnico o sistema recebe esgoto industrial que deveria ser previamente tratado pelas fontes geradoras. Sendo assim é preciso verificar a característica do esgoto proveniente do emissário que liga o distrito industrial e, se for o caso, exigir as adequações dos seus geradores. 


\section{Revista Eletrônica em Gestão, Educação e Tecnologia Ambiental REGET/UFSM (e-ISSN: 2236-1170).}

A eficiência estimada para remoção da carga orgânica do esgoto é de $95 \%$, cujo percentual contradiz com a informação do projeto, em que o percentual máximo atinge $90 \%$.

O memorial de cálculo da vazão da lagoa aerada, concentração de DBO [demanda química de oxigênio], tempo de detenção do esgoto no sistema ( 3 a 3,6 dias conforme sua geração), altura de lâmina d'água $(14,6 \mathrm{~cm})$ etc. contém indicadores de final de plano (2023), quando o monitoramento do desempenho do sistema também os exige para o início de plano (2010, 2011 etc.).

O projeto propôs a utilização de aeradores de 30 HP que tem um diâmetro de zona de mistura completa de $30,0 \mathrm{~m}$ para lagoas com $3 \mathrm{~m}$ de profundidade. Como a lagoa aerada da ETE Cravinhos tem $1 \mathrm{~m}$ a mais se aplicou um fator de correção determinando, então, a quantidade de 12 (doze) aeradores (potência total: $360 \mathrm{HP}$, ou 9,14 W/m³) para atender as dimensões da lagoa, dispostos com espaçamento longitudinal de $26,25 \mathrm{~m}$ e transversal de $23,30 \mathrm{~m}$. Aqui cabem duas observações. Segundo o responsável técnico da ETE estão funcionando "11 (onze) aeradores de maneira alternada", e não os 12. Neste caso se infere que o diâmetro da zona de mistura não está sendo plenamente atendido, fato este que implica numa deficiência de funcionamento do sistema e, por efeito, não atende os indicadores estabelecidos para o tratamento do esgoto. Na visita técnica do autor desta pesquisa, no dia 6/10/11, havia dois aeradores parados.

O conteúdo do projeto não faz referência ao painel elétrico que aciona os aeradores, cujos dados constam apenas de uma planta a ele anexada. Para o responsável técnico da operação do empreendimento, a capacidade de carga instalada, de energia elétrica, é insuficiente para atendê-lo de modo pleno. Esse seria o motivo de apenas 11, e não 12 aeradores estarem operando.

O projeto não explicita o embasamento teórico, ou prático, da recomendação de interromper o funcionamento dos aeradores, salvo por economia de energia, no horário de pico, das $17 \mathrm{~h} 00$ às $20 \mathrm{~h} 00$, sem afetar o desempenho do tratamento do esgoto. Por outro lado, de acordo com o projeto, o teor de oxigênio durante a aeração pode variar entre $2,0 \mathrm{mgO}^{2} / \mathrm{L}$ a 2,5 $\mathrm{mgO}^{2} / \mathrm{L}$, ao contrário é possível a emanação de maus odores [espalhando-se pela atmosfera podendo atingir os bairros adjacentes].

Pela revisão da literatura sobre o tema e a análise do projeto da ETE se constata que o sistema de tratamento de esgoto, de modo geral, ocorre num fluxo contínuo conforme segue: gradeamento - caixa de areia - complexo de lagoas - emissário - ribeirão Preto (deságue).

Deve-se lembrar que o Manual de Operação da ETE prevê o bombeamento anual do lodo da lagoa de sedimentação até as lagoas de lodo, para drenagem, e desidratação do líquido, que é bombeado para o início do sistema de tratamento. E posteriormente é feita a remoção do sólido, numa freqüência anual, para aterro sanitário classe II. Em razão de Cravinhos não dispor de aterro sanitário esta remoção deve ser feita para aterro de outra localidade. O projeto previu a geração de lodo na ordem de 204 toneladas anuais, ou 24, a cada dois meses. Também indica como medida de proteção à contaminação do subsolo da lagoa a aplicação, e compactação, de camada de 0,30 m de argila, e impermeabilização, com manta de polietileno de alta densidade, com 0,005 $\mathrm{m}$ de espessura, sob camada drenante de brita e areia. Acima desta camada devem ser assentados tijolos, em forma de espelho, visando prevenir a remoção da areia quando da limpeza.

O projeto prevê que as lagoas serão utilizadas uma por vez, durante um ano, até a remoção dos sólidos para aterro sanitário através de trator pá carregadeira, e caminhão basculante. $\mathrm{O}$ acesso a elas se dá por rampa previamente construída, e recoberta com manta asfáltica. 


\section{Revista Eletrônica em Gestão, Educação e Tecnologia Ambiental REGET/UFSM (e-ISSN: 2236-1170).}

O fato de a lagoa operar a céu aberto e, nos dias chuvosos, ingressar água de chuva, às vezes, de modo abundante, o projeto não menciona o acréscimo de vazão no dimensionamento da ETE [a parte líquida do efluente deveria ser bombeada para o inicio do sistema]. Como se não bastasse não se construiu o sistema de tratamento do lodo, nem se pavimentou a rampa de acesso à lagoa.

A caixa de recepção e divisão de vazão, instalada entre a lagoa aerada e as duas de sedimentação, funciona por meio de dois vertedouros (dispositivo para escoar o esgoto após determinado nível) dotados de comportas. Na visita técnica do autor do presente estudo, no dia $6 / 10 / 11$, se constatou que não foi previsto, no projeto, um dispositivo para desviar o esgoto por ocasião do serviço de manutenção periódica. Na opinião do técnico responsável pela ETE, devido o potencial corrosivo do esgoto, a comporta instalada precisaria ser de aço inox e não de aço carbono. Diante disso pode-se inferir que seu funcionamento inadequado afetaria a eficiência do sistema, como, por exemplo, numa situação de falha continuada, alteraria o tempo de detenção, de um a dois dias, do efluente. E, por efeito, propiciaria o crescimento de algas.

É importante lembrar que o projeto previu a fixação de um vertedouro, em cada lagoa, numa altura de $3,55 \mathrm{~m}$, a qual deve ser ajustada, periodicamente, conforme a alteração da vazão.

O início da operação dessa planta de tratamento de esgoto completou um ano no final novembro de 2011. Em teoria, 90\% dos sólidos do esgoto serão retidos na lagoa de sedimentação, com estimativa, ao final do plano (2023), de geração de 407 toneladas de lodo, a ser removida a cada dois anos. O projeto sugere a remoção de 1 a 5 anos sem explicitar o critério de cálculo, e a fonte bibliográfica, e o Manual de Operação, já citado, determina seu bombeamento anual. Neste caso torna-se imprescindível conferir, de imediato, sua situação real visando subsidiar o plano de manejo desse material. Essa medida se faz necessária por existir relação entre tais valores e a eficiência do sistema de tratamento. É preciso salientar que o manejo, e armazenamento provisório, do lodo, no interior da planta e sua destinação final devem respeitar as normas técnicas, e a legislação, que lhe são pertinentes.

O Manual de Operação determina a execução do seguinte procedimento para o inicio de funcionamento do sistema de tratamento de esgoto:

A partida do sistema de tratamento deve ocorrer com as lagoas cheias de água do ribeirão Preto para que se possa detectar qualquer falha de funcionamento, tanto dos equipamentos como bombas, aeradores, etc., bem como qualquer tipo de vazamento ou infiltração que possa vir a ocorrer. [...] Todos os aeradores, painéis de controle e bombas deverão ser testados, e no caso de problemas, deverão ser reparados ou substituídos (ECOSSYSTEMS, 2004).

O item em questão também oferece a seguinte recomendação:

$\mathrm{Na}$ ocorrência de vazamento ou mesmo de infiltração, deverá ser efetuado o esgotamento de toda a água, seguindo-se da impermeabilização do local da infiltração ou vazamento e um novo enchimento da lagoa, caixa de passagem ou distribuição com água limpa. Tal procedimento deverá ser realizado a fim de se verificar o real saneamento do problema. Somente após essa garantia o sistema poderá ser abastecido com esgoto doméstico. Após as verificações e solucionamento dos problemas, a lagoa aerada deverá estar cheia com águas do ribeirão Preto para receber os esgotos domésticos. A partir do início do lançamento dos esgotos na lagoa, os aeradores deverão ser ligados [...]. Para o início do lançamento do esgoto no sistema de tratamento, não deverá ser esvaziada as outras lagoas, já cheias de água em função dos testes. Os esgotos serão misturados com a água e tratados normalmente pelo sistema (ECOSSYSTEMS, 2004). 


\section{Revista Eletrônica em Gestão, Educação e Tecnologia Ambiental REGET/UFSM (e-ISSN: 2236-1170).}

Tais recomendações dispensam comentários uma vez que se trata de procedimento técnico de imperioso cumprimento pelos responsáveis da construção e operação da ETE, a fim de não só garantir a eficiência do sistema, como, também evitar problemas futuros.

O Manual de Operação determina levantamento de dado microbiológico e físico químico da água do ribeirão Preto, numa frequência mensal e semestral, propondo-se obter indicadores do funcionamento da ETE. Cumpre esclarecer que o Manual menciona que o ribeirão Preto é classe II, mas, contraditoriamente, o item 10 do projeto o enquadra como classe IV baseando-se no Decreto Estadual no 10.755/1977.

No projeto se constatou que para calcular a dimensão da caixa de areia tomaram-se por base os dados da ETE Pinheiros, localizada na capital paulista, os quais foram ajustados para a vazão de $111,1 \mathrm{l} / \mathrm{s}$ com produção de 0,113 litros de areia por $\mathrm{m}^{3}$ de esgoto. Cumpre dizer que além de não ter sido justificado o critério adotado, os números de vazão até então utilizados, pelo autor, são 69,4 l/s (início de projeto), e 92,6 l/s (fim de projeto).

Em função do critério de dimensionamento da calha Parshall o projeto, determinou a característica da grade de retenção de dejetos sólidos, e a altura da lâmina de esgoto, sendo, portanto, 0,47 $\mathrm{m}$ a montante e 0,37 $\mathrm{m}$ (hipótese de metade da grade estar obstruída), a jusante desta. O projeto não considerou o aumento de vazão, por ocasião de dias chuvosos, e a possibilidade de ingresso, indevido, de água pluvial no trajeto fonte geradora-ETE.

O resultado do estudo de autodepuração, de final de plano (2023), do ribeirão Preto, após lançamento do esgoto tratado é positivo. Ele tem por hipótese um valor de $0,60 \mathrm{mg} / \mathrm{l}$ de concentração de Oxigênio Dissolvido (OD), superando os $0,50 \mathrm{mg} /$ fixados no Decreto Estadual $\mathrm{n}$ 은 8.468/1976 (CETESB, 2011). Portanto, este indicador deve ser monitorado, com periodicidade mensal e semestral (mais abrangente), conforme o Manual de Operação, o que contribuirá na orientação do gerenciamento da ETE. Neste caso é preciso considerar a vazão real do corpo receptor constituída das contribuições de seus efluentes, a montante, conforme citação, do projeto.

O conteúdo do projeto não faz referência ao paisagismo, e ao sistema de drenagem da ETE, cujos dados constam de uma planta a ele anexada. Vale lembrar que esta planta prevê a implantação de cerca viva, paralela à estrada municipal, e de formação de bosque, com árvores, no trecho entre o alambrado e o ribeirão Preto. Na planta em questão não constam a implantação de cerca viva nos trechos situados à esquerda, e à direita, da cerca de quem olha da estrada para o interior da ETE. É importante frisar que a implantação de cerca viva, em todo o perímetro do empreendimento, foi citada no projeto como elemento de prevenção dos odores que poderão ser emanados na operação do sistema, sem a qual este elemento poluidor atingiria os bairros adjacentes.

$\mathrm{Na}$ visita técnica do dia 6/10/11 observou-se que os taludes estão tomados por braquiária (um tipo de capim para pastagem), no lugar de grama. Já o trecho entre o alambrado e o ribeirão Preto foi tomado por vegetação invasora.

Quanto à drenagem, a planta apresenta apenas um detalhe da canaleta (meia cana) de concreto, de $0,30 \mathrm{~m}$, dispositivo este insuficiente para conduzir o escoamento da água de chuva incidente. $\mathrm{E}$, talvez por isso, já se instalou processo erosivo em vários trechos, inclusive nos acessos, nas áreas de circulação e estacionamento, assim como nas bermas, e nos taludes, das lagoas de sedimentação e lodo (situação em 6/10/11). 


\section{Revista Eletrônica em Gestão, Educação e Tecnologia Ambiental REGET/UFSM (e-ISSN: 2236-1170).}

Não constou do projeto menção ao Plano de Contas para gerenciar os custos operacionais e administrativos, de manutenção preventiva e corretiva, com definição de forma de custeio da operação e manutenção do sistema de tratamento de esgoto [de onde virá o dinheiro].

Entre as lacunas evidenciadas nesta pesquisa deve ser considerado o fato de a ETE estar sendo operada sem outorga, do uso do ribeirão Preto, para sua finalidade, e sem licença de operação, pelos órgãos públicos responsáveis.

\section{CONSIDERAÇÕES FINAIS}

A revisão da literatura descreveu o tratamento de esgoto por aeração prolongada, como é o caso da ETE de Cravinhos, em duas etapas, ou seja, de tratamento prévio e secundário.

As vantagens desse sistema são constituídas de economia de área de implantação, maior eficiência no tratamento e flexibilidade de operação. As desvantagens, por sua vez, estão relacionadas a custo maior, operação mais delicada e controle diário por meio de análises de laboratório.

Com base nos documentos analisados constata-se a existência de inconformidades, e ou lacunas, entre os dados de projeto e a realidade operacional da ETE, ante aos padrões de eficiência citados.

Ponderando os fatos elencados nesta pesquisa é inegável que a eficiência da ETE está diretamente relacionada ao funcionamento integrado, e preciso de todas as etapas, as quais devem estar dimensionadas e executadas com exatidão.

\section{AGRADECIMENTO}

O autor desta pesquisa agradece à Fundação de Amparo à Pesquisa do Estado de São Paulo pelo apoio recebido para um projeto de pesquisa maior que possibilitou a elaboração do presente trabalho.

\section{REFERÊNCIAS BIBLIOGRÁFICAS}

ANDRADE, M. M. Introdução à metodologia do trabalho científico. São Paulo: Atlas, 2001.

BORJA, P. C.; MORAES, L. R. S. Saneamento como um direito social. Disponível em: <http://www.semasa.sp.gov.br>. Acesso em: 25 nov. 2011.

CASAN - Companhia Catarinense de Águas e Saneamento. Estação de Tratamento de Esgoto - ETE. Disponível em: <http://www.casan.com.br>. Acesso em: 24 nov. 2011.

CETESB - Companhia de Tecnologia de Saneamento Ambiental. Decreto no 8.468/1976. Disponível em: <http://www.cetesb.sp.gov.br>. Acesso em: 24 nov. 2011.

ECOSSYSTEMS Limitada. Projeto da Estação de Tratamento de Esgotos Domésticos de Cravinhos (SP). Ribeirão Preto: Ecossystems, 2004.

IBGE - Instituto Brasileiro de Geografia e Estatística. Pesquisa nacional por amostra de domicílios 2008. Disponível em:<http://www.ibge.gov.br>. Acesso em: 11 nov. 2011.

2011.a

. Fecundidade, natalidade e mortalidade. Disponível em: <http://www.ibge.gov.br>. Acesso em: 11 nov. 2011.

MICHAELLIS- minidicionário da língua portugesa. São Paulo: Melhoramentos, 2000.

SEADE - Fundação Sistema Estadual de Análise de Dados. Perfil municipal. Disponível em: <http://www.seade.gov.br>. Acesso em 13 nov. 2011.

WIKIPÉDIA. Cravinhos. Disponível em: <http://pt.wikipedia.org>. Acesso em 13 nov. 2011.

VERGARA, S. C. Projetos e relatórios de pesquisa em Administração. São Paulo: Atlas, 1997. 